\title{
Surface roughness and color measurements of glazed or polished hybrid, feldspathic, and Zirconia CAD/CAM restorative materials after hot and cold coffee immersion
}

Lujain I. Aldosari ${ }^{1}$, Abdulkhaliq A. Alshadidi ${ }^{2}$, Amit Porwal ${ }^{3}$, Nasser M. Al Ahmari ${ }^{1}$, Mohammed M. Al Moaleem ${ }^{3^{*}} \mathbb{E}$, Ahmed M. Suhluli ${ }^{4}$, Mansoor Shariff ${ }^{1}$ and Ahmed O. Shami ${ }^{4}$

\begin{abstract}
Background: The purpose of this study evaluates and compares the effect of surface roughness (Ra) and color stability on computer-aided design/computer-aided manufacturing (CAD/CAM) hybrid resin (Vita Enamic), feldspathic (Vitablocs ${ }^{\circledR}$ Mark II), and lithium disilicate Zirconia (Vita Suprinity) glazed or polished ceramics immersed in hot Arabic Qahwa and cold coffee.

Methods: A total of 96 standardized samples were prepared from CAD/CAM restorative materials. Half of the samples were polished as per the manufacturer's instructions using a porcelain polishing kit, and the other half were glazed. Samples were distributed and immersed in hot Arabian Qahwa and cold coffee followed by thermocycling. Ra measurements and color changes were conducted before and after immersion. SEM images were captured from each type of glazed or polished ceramic. One-way ANOVA paired Student's t-test, and Bonferroni test were conducted to detect significant difference between the groups. $P>0.05$ was a significant level.
\end{abstract}

Results: Of all the tested samples, Ra increased without any significant difference; however, mean color changes $\left(\Delta E^{*}\right)$ showed significant differences. An increase in Ra was noted for all the glazed and polished samples after immersion and thermocycling. However, differences were significant only in VM II. In addition, $\Delta E^{*}$ was significant only in Vita Suprinity (VS) samples. For immersion groups, significant Ra changes were noticed in glazed samples, only in Vita Enamic (VE) with no $\Delta E^{*}$. In polished samples, mean Ra changes were observed in VM II and VS samples. Significant differences were also noticed in polished $V E$ and $V S$ subgroups of $\triangle E^{*}$.

Conclusions: Ra affects all the tested samples, providing higher values on the polished specimens. The $\Delta E^{*}$ caused by hot Arabic Qahwa and cold coffee on glazed or polished CAD/CAM restorative materials were clinically acceptable.

Keywords: Arabic Qahwa, Cold coffee, CAD/CAM, Surface roughness

*Correspondence: drmoaleem2014@gmail.com

${ }^{3}$ Department of Prosthetic Dental Science, College of Dentistry, Jazan

University, Jazan 45142, Kingdom of Saudi Arabia

Full list of author information is available at the end of the article

\section{Background}

In the last few years, patients are increasingly demanding long-term color stability of aesthetic restorations to improve teeth appearance [1-3]. To meet the demand, computer-aided design/ computer-aided manufacturing (CAD/CAM) materials have been developed to fabricate the all-ceramic restoration materials. Over the last 
decades, the CAD/CAM systems have enhanced new all-ceramic materials for the restoration of the esthetic zone, attributed to the restoration of aesthetics or clinical longevity [4]. Dental hybrid-based ceramic is one of the most popular used material to fabricate all-ceramic prostheses in modern dental practice owing to the benefits in term of higher mechanical properties [5-7] and outstanding biocompatibility compared to other ceramic restorative materials [8-10].

The surface roughness $(\mathrm{Ra})$ and the color stability are other successes of the restorations in the esthetic zone area. Ra values are used to assess Ra materials and compare their efficacy [11]. Alp et al. [12] showed that the surface treatments using the Vita Suprinity (VS) restorative materials are clinically acceptable for color changes after coffee staining and thermocycling. Egilmez et al. [13] stated that CAD/CAM Vita Enamic (VE) restorative materials exhibited different $\mathrm{Ra}$ values and surface topographies. After immersion in Khat extract, another study found lower Ra values for glazed or polished metalceramic as compared with glazed Vitablocs Mark II (VM II) [14]. Some studies concluded that low fusing or feldspathic porcelain had stable surfaces after immersion in different staining materials [15-18]. Al Moaleem et al. [14] showed a higher significant effect on Ra of CAD/ CAM Zirconia compared to feldspathic ceramic, manually or machinable packed CAD/CAM materials.

An excellent aesthetic ceramic restoration is desired. In addition, maintaining the protheses' color stability is crucial in the oral environment. Kursoglu et al. [19] claimed that diet, immersion time, and categories of porcelain surface were responsible for prosthetic material discoloration. However, other studies evaluated the color porcelain materials stability concerning the surface texture, concluding that accurate polishing procedures could create smooth ceramic surfaces similar to glazed surface [20, 21]. Polishing techniques as an alternative to glazing have also been suggested [19-21].

The CIE Lab color system is global color research that interprets clinically values of colors and differences in color changes $\left(\Delta \mathrm{E}^{*}\right)$. Based on the color-magnitude between two objects, color spaces are comprised of three coordinates: L*(lightness, brightness, black/white color character), $\mathrm{a}^{*}$, and $\mathrm{b}^{*}$ (chromatic color characters) [22-24].

Coffee causes discoloration to all-ceramic prostheses. Gupta et al. [20] evaluated the ceramic materials' color stability after exposure to commonly consumed beverages i.e., tea, coffee, and Coca-Cola. They concluded that dietary beverages affected the ceramic restorations. Alghazali et al. [22] discovered that Arabic coffee changed the color of different types of ceramic materials either glazed or polished forms. In addition, coffee immersion significantly changed Zirconia ceramic colors [12, 18, 25].

Coffee is one of the most popular consumed beverages worldwide. The Saudi population consumes a special type of coffee called "Arabian Qahwa". It contains some additives: Saffron, Ginger, and Cardamom. However, Arabian Qahwa is a discoloration drink due to additive constituents, which affects teeth stain during aesthetic restorations [22, 26]. With an increase in coffee consumption in Saudi and globally, esthetic restorative procedures are crucial to conserve the maximum amount of original quality teeth. Recent studies evaluate materials for aesthetic restorations. However, few focused on the recent advanced CAD/CAM materials for aesthetic restorations of the Arabic Qahwa and cold coffee consumers.

This in-vitro study aimed to assess the effect of glazing or polishing on Ra and color stability of resin matrix glass-ceramic VE, feldspathic ceramic (Vitablocs ${ }^{\circledR}$ Mark II), and lithium disilicate Zirconia (Vita Suprinity) CAD/ CAM restorative ceramic materials following exposure to staining solutions, such as Arabic Qahwa (hot) and cold coffee drinks along with thermocycling.

Null hypothesis: No mean color changes $\left(\Delta \mathrm{E}^{*}\right)$ or mean Ra changes in the CAD/CAM restorative materials groups and the individual group after surface treatment, immersion solutions, and thermocycling. In the current study, comparison of the results will be calculated based on 50: $50 \%$ perceptibility and acceptability thresholds (AT and PT).

\section{Methods}

\section{Study design}

The design included different glazed or polished CAD/ CAM all-ceramic samples (96 overall) to simulate oral cavity, assess changes in the surface roughness and color after immersion (30 days) in hot Arabic Qahwa, cold (Frappuccino) coffee drink, and thermocycling. Table 1 presents the materials and devices. Figure 1 presents the flow chart of the study design, steps, and sample distributions.

\section{Sample preparations and distributions}

A total of 96 samples were prepared; 32 samples were CAD/CAM all-ceramic restorative materials i.e., Vita Enamic, Vitablocs Mark II, and Vita Suprinity (VITA Zahnfabrik, Bad Säckingen, Germany). Thirty-two discs of standardized dimensions comprising of each restorative material of controlled/uniform size were milled, consisting of $10 \mathrm{~mm} \times 10 \mathrm{~mm} \pm 0.2$ diameters and thickness in the range of $2.0 \pm 0.2 \mathrm{~mm}$, following the manufacturer's instructions using a CAD/CAM machine (Amann Girrbach, Germany) and glazed (Fig. 1). 


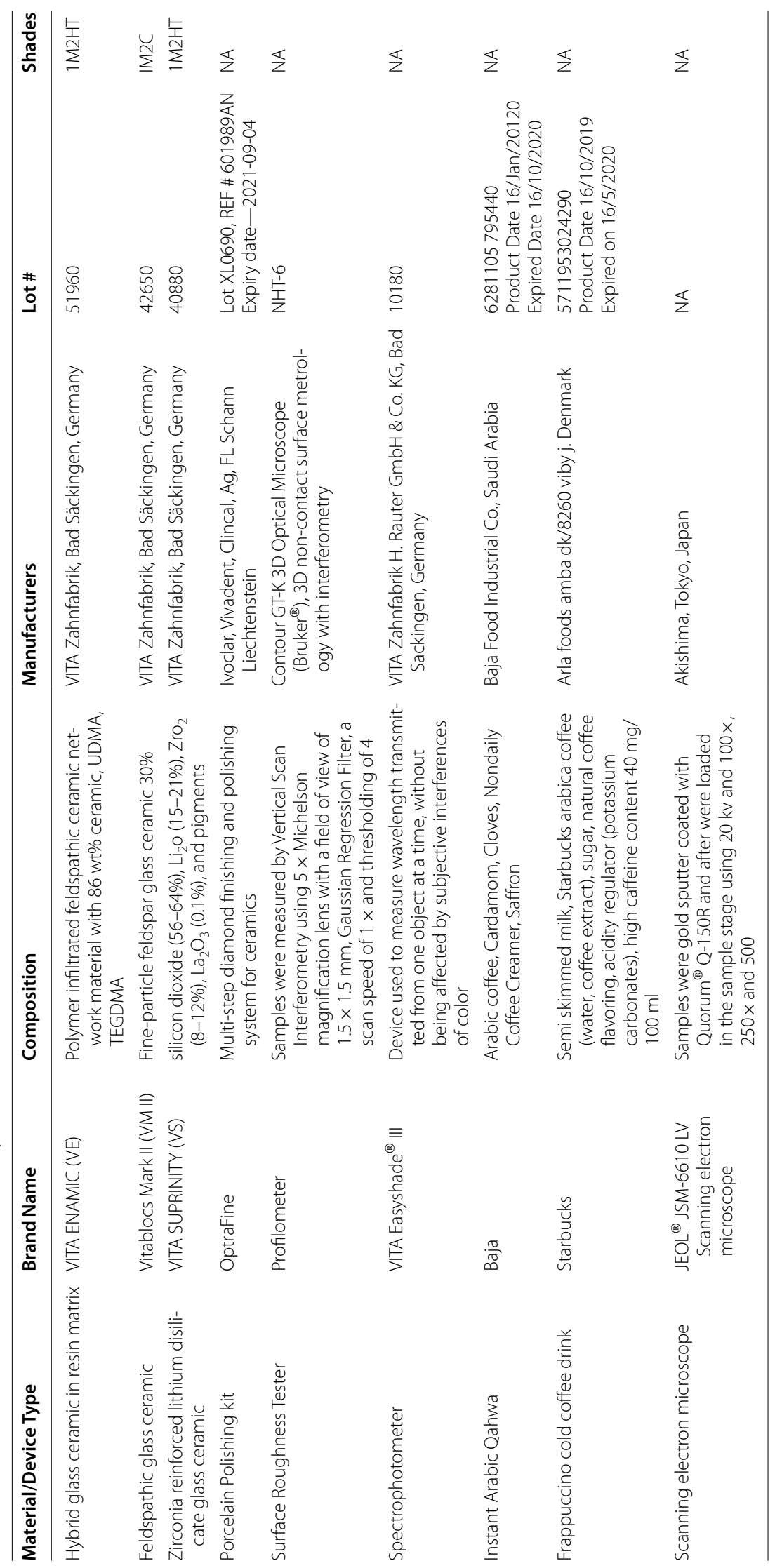




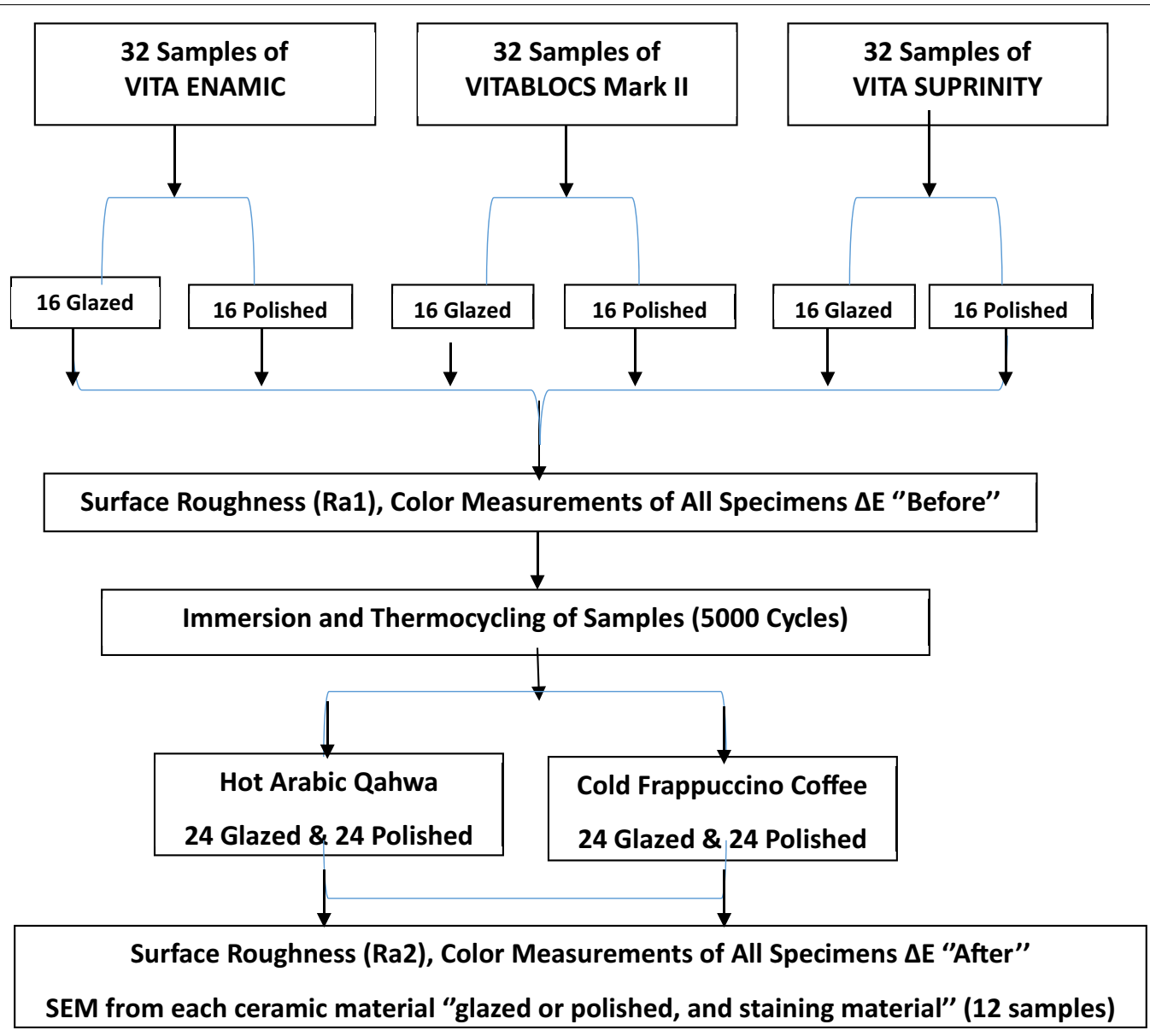

Fig. 1 Study design and sample distribution of all CAD/CAM materials along with the surface treatments and measurements (Ra and $\triangle E$ and SEM)

\section{Surface treatments of samples}

Each group was divided into two equal subgroups of 16 each. One subgroup was obtained as glazed from the laboratory, and further measurements were carried out without any surface treatments. Another subgroup (16 each) was polished with an OptraFine polishing kit (Ivoclar, Vivadent, Germany), as per the manufacturer's instructions under constant load $(2 \pm 0.25 \mathrm{~kg})$ using an equal number of grinders in a single direction [27]. Polishing steps are first, finishing $=\mathrm{F}$ (light blue), second polishing $=\mathrm{P}$ (dark blue). The maximum polishing speed for the used handpiece was 15,000 RPM, which comprised of water spray followed by high Gloss Polishing brush (HP), with a speed of 5000-7000 rpm (Maximum 10,000 rpm) without water and with OptraFine HP Polishing Paste. Sample surfaces were modified to mimic the clinical adjustment of ceramic restorations and polished. A single operator (M.M.) dealt with the specimens according to the instruction presented in the leaflet of each CAD/CAM all-ceramic type.

\section{Surface roughness measurements}

The characterizations and imaging were performed using a Contour GT-K 3D Optical Microscope $\left(\right.$ Bruker $\left.^{\circledR}\right)$, a 3D non-contact surface metrology with interferometry. Samples were measured by Vertical Scan Interferometry using a $5 \times$ Michelson magnification lens with a field of view of $1.5 \times 1.5 \mathrm{~mm}$, Gaussian Regression Filter, a scan speed of $1 \mathrm{x}$, and thresholding of 4 . Samples were placed on the profilometer device and manually adjusted to give an image on the monitor screen. The microscope used Vision 64 $\left(\right.$ Bruker $\left.^{\circledR}\right)$ software to control the instrument settings, data analyses, and graphical output. The measurement was performed using vertical scanning interferometry, using broadband (normally white) light source, effective for measuring objects with rough surfaces and objects with adjacent pixel-height differences greater than $135 \mathrm{~nm}$. Each sample was scanned at 3 given points and averaged accordingly to determine the Ra value in micrometer $(\mu \mathrm{m})$. This was considered as Ra1 value before 
immersion. Ra measurements followed the ISO 11562 recommendations for standardization [11].

\section{Color measurements}

Color measurements were in the gray background for all the samples using a single operator (M. M.) with the help of Easyshade Vita probe spectrophotometer (VITA Easyshade $^{\circledR}$ III, VITA, Germany). All the samples were measured for the CIE-Lab values to provide the numerical values of the $3 \mathrm{D}$ color measurements. $L^{*}, a^{*}$, and $b^{*}$ values for all the samples were measured thrice, and the average value was considered as $\Delta E^{*}$. The values were presented in the means of the color data and standard deviation (SD) as discussed previously [14, 22-24].

\section{Sample immersion and thermocycling}

Following $\mathrm{Ra}$ and color measurements, samples from two subgroups i.e., polished and glazed subgroups from each $\mathrm{CAD} / \mathrm{CAM}$ all-ceramic restorative material were further divided. Half of the samples were immersed in hot Arabic Qahwa and half in a cold Frappuccino cold coffee drink along with thermocycling.

Instant hot Arabic Qahwa was a form of Nitrogen Flushed Packet for single use. The immersion solution was prepared for each packet $(30 \mathrm{~g})$, mixing with 1-L boiled water at $100 \mathrm{C}^{0}$ jack, then boiled for $15 \mathrm{~s}$. Starbucks Frappuccino cold coffee drink is readily available in a sealed bottle, to be shaken well and used. All the samples were immersed, and thermocycling was performed. Fresh solutions were used daily for the samples ready to be immersed. [22, 24, 25] During immersion, the aging process was performed at a temperature between 5 and $55{ }^{\circ} \mathrm{C}$ with a total number of 5000 cycles. Following the aging process for 30 days, all the samples were dipped in distilled water 10 times, wiped with tissue paper, and left to dry.

Subsequently, the surface roughness (R2) and color measurements were again carried out with the same instruments and registered as post-aging readings. The mean $\mathrm{Ra}$ was calculated before and after immersion (R2R1). However, mean average color changes $\left(\Delta E^{*}\right)$ values were calculated using the following equation: " $\Delta \mathrm{E}^{*}=[(\mathrm{L}$ $\left.\left.1^{*}-\mathrm{L}^{*}\right)^{2}+\left(\mathrm{a} 1^{*}-\mathrm{a} 2^{*}\right)^{2}+\left(\mathrm{b} 1^{*}-\mathrm{b} 2^{*}\right)^{2} 2\right]^{1 / 2} \stackrel{(}{ }(14,22-25)$.

\section{Scanning electron microscope images}

A tested glazed or polished sample material and different immersed stain materials were selected for SEM capturing. The samples were gold sputter-coated with Quorum ${ }^{\circledR}$ Q-150R (East Sussex, BN8 6BN, United Kingdom). Then, the samples were loaded into the specimen's stage of the JEOL $^{\circledR}$ JSM-6610 LV (Akishima, Tokyo, Japan). Samples were scanned and images captured with a Scanning Electron Microscope using $20 \mathrm{kv}$ and $250 \times$ magnification.

\section{Statistical analysis}

Mean, $\mathrm{SD}$ of $\mathrm{Ra}$, and average $\Delta E^{*}$ of glazing and polishing for $\mathrm{CAD} / \mathrm{CAM}$ all-ceramic restorative samples of $\mathrm{VE}$, VM II, VS were recorded before and after immersion in hot Arabic Qahwa, cold Frappuccino coffee drink, and thermocycling. Microsoft Excel 13 software was used to input the data and analyzed using Statistical Package for Social Science (SPSS) version 22.0 (SPSS Inc., Chicago IL, USA). One-way ANOVA paired Student's t-test, and Bonferroni test were applied to detect any significant difference between the groups. $\mathrm{P}>0.05$ was set at the significant level. Then, $\Delta E^{*}$ values were linked and compared to reach a clinically acceptable threshold of 4.2 units as mentioned in the previous study. [23] Both ANOVA and Student $\mathrm{t}$-test have been used to compare the values of the color changes or differences between different groups as well as in between intervals time, and also compared color changes of every single group to $50: 50 \%$ perceptibility and acceptability thresholds to assess if such colour changes are clinically acceptable.

\section{Results}

The mean changes and the Ra SD of the tested ceramic restorative materials were between 0.56 and $0.59 \mu \mathrm{m}$. No significant differences were noticed between the tested materials and $\mathrm{p}$-value $<0.940$. The highest $\Delta \mathrm{E}^{*}$ and $\mathrm{SD}$ were in the VE group $(3.07 \pm 0.49)$, followed by the VM II and VS [(2.65 \pm 0.26$)$ and $(1.96 \pm 0.64)]$. Additionally, the ANOVA test for $\Delta \mathrm{E}^{*}$ exhibited a statistically significant difference between ceramic materials with $\mathrm{p}$-values $<0.001$ (Table 2). The Bonferroni post hoc test was conducted for multiple comparisons between the three CAD/CAM restorative materials, which showed significant differences in the $\triangle \mathrm{E}$ values between the tested CAD/CAM restorative materials with a $\mathrm{p}$-value $<0.001$. However, other parameters show no significant differences.

By comparing surface materials, the Ra means was nearly the same for the three tested types of ceramic and their surface treatment type. The Ra rang was between $0.51 \pm 0.52 \mu \mathrm{m}$ and $0.35 \pm 0.31 \mu \mathrm{m}$ for the glazed specimens. However, it was in the range of $0.76 \pm 0.63 \mu \mathrm{m}$ and $0.67 \pm 0.38 \mu \mathrm{m}$ for polished specimens of the ceramic materials (Table 3 and Fig. 2). The $\Delta E^{*}$ values of glazed and polished VE were the highest $\Delta \mathrm{E}^{*}(3.03 \pm \mathbf{0 . 5 9}$ and $3.12 \pm \mathbf{0 . 3 8}$ ), whereas the lowest was for glazed and polished VS $(1.68 \pm \mathbf{0 . 6 1}$ and $2.23 \pm \mathbf{0 . 5 6})$. Student t-test showed a significant difference between glazed and polished VM II in the mean Ra with a p-value $<0.025$. However, the $\Delta \mathrm{E}^{*}$ values are between the glazed and polished VS with a p-value $<0.012$ (Table 3 and Fig. 3).

The highest Ra means and SD for cold coffee were $1.20 \pm 0.57$ and $1.00 \pm 0.20$ for polished VM II and 
Table 2 Mean and standard deviation (SD) of surface roughness (Ra), and mean color change ( $\left.\triangle \mathrm{E}^{*}\right)$ values of ceramic materials before and after coffee immersion and thermocycling (ANOVA test between and within the groups)

\begin{tabular}{|c|c|c|c|c|c|c|}
\hline Parameter & Mean \pm SD & Ceramic Type & Vita Enamic & Vitablocs Mark II & Vita Suprinity & $P$ value \\
\hline \multirow[t]{3}{*}{ S Roughness Pre (Ra1) } & $1.78(0.55)$ & Vita Enamic & - & 0.436 & 1.000 & 0.111 \\
\hline & $1.55(0.46)$ & Vitablocs Mark II & 0.436 & - & 0.126 & \\
\hline & $1.86(0.76)$ & Vita Suprinity & 1.000 & 0.126 & - & \\
\hline \multirow[t]{3}{*}{ S Roughness Post (Ra2) } & $2.37(0.41)$ & Vita Enamic & - & 0.267 & 1.000 & 0.077 \\
\hline & $2.11(0.63)$ & Vitablocs Mark II & 0.267 & - & 0.095 & \\
\hline & $2.44(0.73)$ & Vita Suprinity & 1.000 & 0.095 & - & \\
\hline \multirow[t]{3}{*}{ Mean Roughness Changes (Ra) } & $0.59(0.40)$ & Vita Enamic & - & 1.000 & 1.000 & 0.940 \\
\hline & $0.56(0.53)$ & Vitablocs Mark II & 1.000 & - & 1.000 & \\
\hline & $0.58(0.38)$ & Vita Suprinity & 1.000 & 1.000 & - & \\
\hline \multirow[t]{3}{*}{ Mean Color Changes $(\triangle \mathrm{E})$} & $3.07(0.49)^{\mathrm{a}}$ & Vita Enamic & - & $0.002^{*}$ & $0.000^{*}$ & $0.000^{*}$ \\
\hline & $2.65(0.26)^{b}$ & Vitablocs Mark II & $0.002^{*}$ & - & $0.000^{*}$ & \\
\hline & $1.96(0.64)^{c}$ & Vita Suprinity & $0.000^{*}$ & $0.000^{*}$ & - & \\
\hline
\end{tabular}

Different superscripts upper case letters mean statistical difference inside the respective subgroups $(P<0.001)$ based on ANOVA followed by Bonferroni tests

Table 3 Mean and standard deviation (SD) of surface roughness $(\mathrm{Ra})$, and color change $\left(\triangle \mathrm{E}^{*}\right)$ values of the ceramic materials after staining immersion and thermocycling in relation to surface treatment type (t-test)

\begin{tabular}{ll}
\hline Parameter & $\begin{array}{l}\text { Surface treatment } \\
\text { type (Mean } \pm \text { SD) }\end{array}$ \\
\cline { 2 - 2 } & Glazed Polished (t-test)
\end{tabular}

Vita Enamic

Surface roughness Pre (Ra1) $1.57(0.40) \quad 1.98(0.61) \quad 0.033^{*}$

Surface roughness Post (Ra2) $2.08(0.22) \quad 2.66(0.22) \quad 0.000^{*}$

Mean roughness changes (Ra) $0.51(0.52) \quad 0.68(0.49) \quad 0.217$

Mean color changes $\left(\Delta E^{*}\right) \quad 3.03(0.59) \quad 3.12(0.38) \quad 0.609$

Vitablocs Mark II

Surface roughness Pre (Ra1) $1.53(0.53) \quad 1.75(0.39) \quad 0.813$

Surface roughness Post (Ra2) $1.88(0.62) \quad 2.34(0.58) \quad 0.043^{*}$

Mean roughness changes (Ra) $0.35(0.31) \quad 0.76(0.63) \quad 0.025^{*}$

Mean color changes $\left(\Delta \mathrm{E}^{*}\right) \quad 2.62(0.22) \quad 2.68(0.30) \quad 0.592$

Vita Suprinity

Surface roughness Pre (Ra1) $1.38(0.45) \quad 2.35(0.70) \quad 0.000^{*}$

Surface roughness Post (Ra2) 2.05 (0.48) $2.83(0.74) \quad 0.001^{*}$

Mean roughness changes (Ra) $0.48(0.37) \quad 0.67(0.38) \quad 0.157$

Mean color changes $\left(\Delta E^{*}\right) \quad 1.68(0.61) \quad 2.23(0.56) \quad 0.012^{*}$

$*=p \leq 0.05$; Significant

polished VS, respectively. The student t-test is significant among the glazed VE, polished VM Mark II, and polished VS with a $\mathrm{p}$-value $<0.001$. The highest $\Delta \mathrm{E}^{*}$ and $\mathrm{SD}$ values for hot Arabic Qahwa were for glazed VE and polished VM II $(2.90 \pm 0.19$ and $2.73 \pm 0.23)$. However, the lowest effects were for glazed VS $(1.94=0.80)$. The highest $\Delta \mathrm{E}^{*}$ for cold coffee was for polished followed by glazed VE with $3.40=0.30$ and $3.15=0.82$ respectively. The lowest effects were glazed VS $(1.42=0.09)$. The p-values for color changes were significant among the subgroups of polished VE and VS. For multiple comparisons, the one-way ANOVA and Bonferroni post hoc tests showed a significant difference in the mean Ra values among the glazed VE, polished VM II, and VS between immersion types with $\mathrm{p}$-values $<0.016,0.002$, and 0.000 , respectively. A significant difference in $\Delta \mathrm{E}^{*}$ was noted in the polished subgroup of VE and VS in both immersion materials compared with P-values $<0.001$ and 0.003 (Table 4).

The generalized linear model between individual variations and the two-way repeated measurements using ANOVA showed a significant difference for each surface treatment, immersion type interaction between ceramic type and surface treatment protocol as well as immersion type $(P \leq 0.05)$ between the three parameters. However, no significant differences were found regarding the interaction between ceramic ( $\mathrm{Ra}$ ) type and immersion type $\left(\Delta \mathrm{E}^{*}\right)$ (Table 5).

Figure 4 shows the SEM images for all the glazed and polished CAD/CAM materials after immersion and thermocycling. Polished samples have more flaws compared to the glazed ones. In Glazed Hot Arabic Qahwa, the image VM II sample has a smoother surface compared to other ceramic materials. While VE has a smoother surface for polished Cold coffee samples confirming the profilometry measurements.

\section{Discussion}

Patients are increasingly demanding anterior aesthetic restorations owing to their long-term color stability and continuous development for All-ceramic materials. Following consumption of hot and cold beverages, some degree of color changes is noticed. Different types 


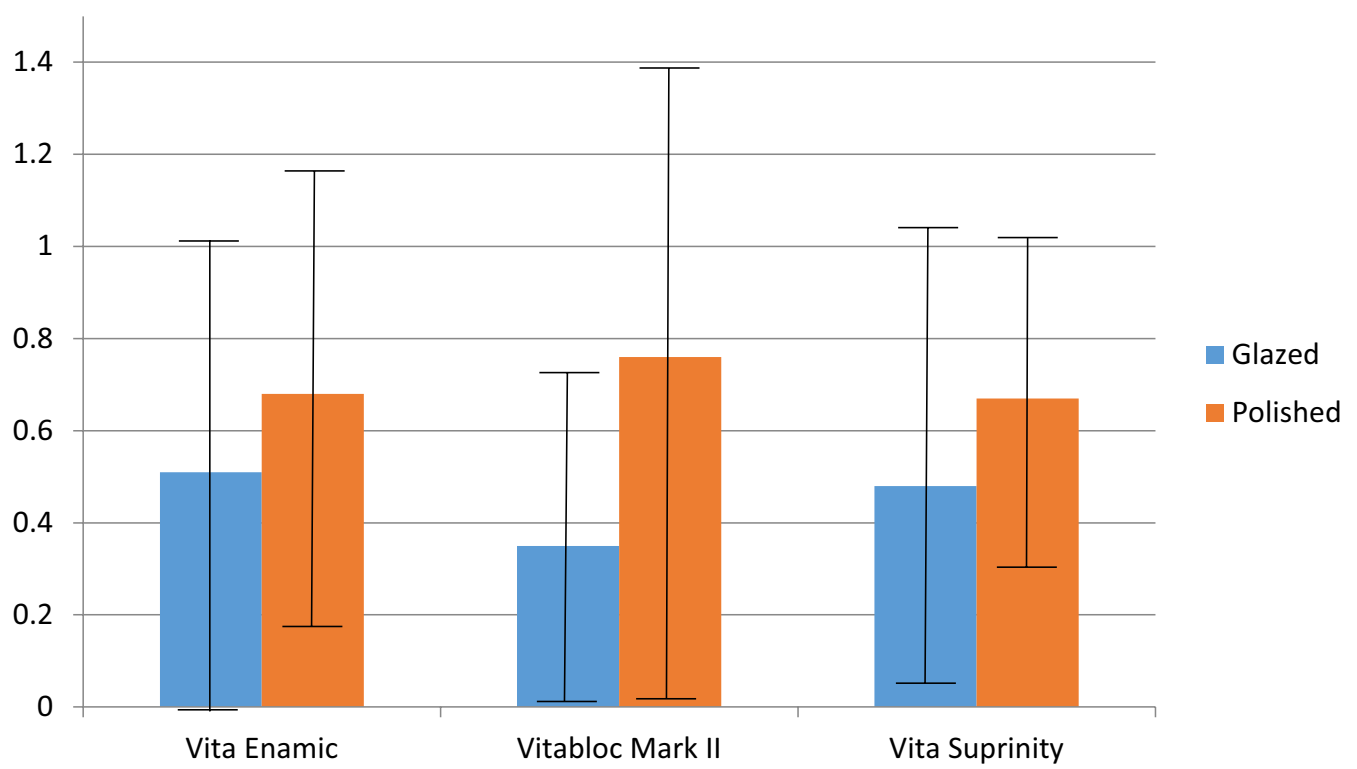

Fig. 2 Bar chart representing the mean and SD of Ra values in relation to surface type (t-test)

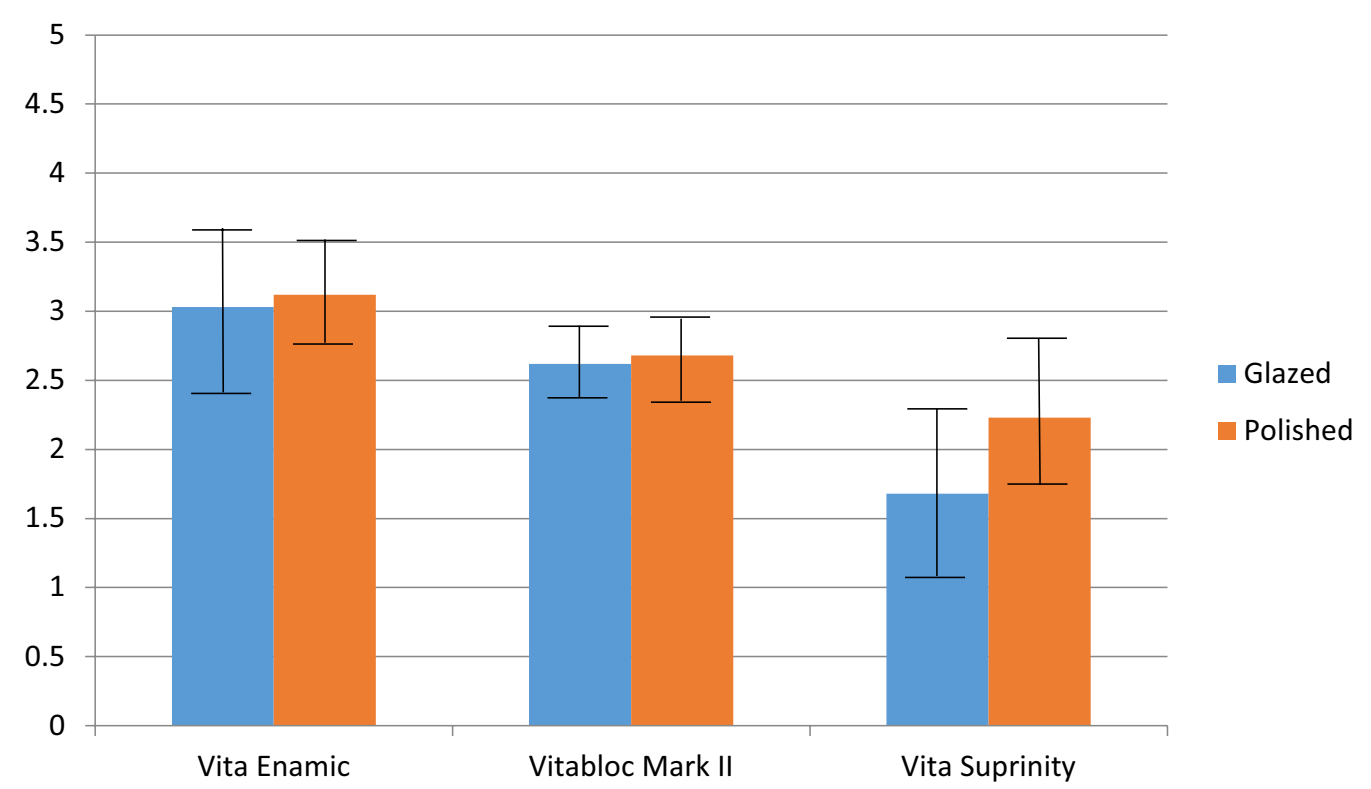

Fig. 3 Bar chart representing the mean and $S D$, and $\Delta E^{*}$ values in relation to surface type (t-test)

of Arabian Qahwa coffees contain Saffron, Ginger, Cardamom, natural coffee flavoring, potassium carbonates, and high caffeine content, which might be a staining factor to the intraoral cemented aesthetic prosthesis $[22,26]$. This in-vitro spectrophotometric study evaluated the effect of surface roughness and color changes on different $\mathrm{CAD} / \mathrm{CAM}$ restorative ceramic materials following immersion in hot Arabic Qahwa and Frappuccino cold coffee drinks separately. The null hypothesis was accepted since no significant difference in $\mathrm{Ra}$ is noticed in correlation to the different groups. However, a significant difference in $\Delta E^{*}$ of tested materials was detected. A significant variance is noticed in mean Ra between glazed VE and polished surfaces of VM II and 
Table 4 Mean and standard deviation (SD) for different types of ceramic with different surfaces treatment types and immersion type (t-test)

\begin{tabular}{|c|c|c|c|c|c|}
\hline $\begin{array}{l}\text { Ceramic and surface } \\
\text { treatment types }\end{array}$ & Immersion type & $\begin{array}{l}\text { Surface roughness } \\
\text { Pre (Ra1) }\end{array}$ & $\begin{array}{l}\text { Surface roughness } \\
\text { Post (Ra2) }\end{array}$ & $\begin{array}{l}\text { Mean roughness } \\
\text { changes ( } \mathrm{Ra})\end{array}$ & $\begin{array}{l}\text { Mean color } \\
\text { changes } \\
\left(\Delta \mathrm{E}^{*}\right)\end{array}$ \\
\hline \multirow[t]{3}{*}{ Vita Enamic Glazed } & Arabic Qahwa & $2.39(0.33)$ & $2.80(0.16)$ & $0.40(0.35)$ & $2.90(0.192)$ \\
\hline & Cold Coffee & $1.57(0.55)$ & $2.53(0.19)$ & $0.96(0.46)$ & $3.15(0.82)$ \\
\hline & $P$ value (t-test) & $0.003^{*}$ & $0.008^{*}$ & $0.016^{*}$ & 0.436 \\
\hline \multirow[t]{3}{*}{ Vita Enamic Polished } & Arabic Qahwa & $1.67(0.48)$ & $2.18(0.32)$ & $0.51(0.31)$ & $2.84(0.20)$ \\
\hline & Cold Coffee & $1.47(0.31)$ & $1.98(0.37)$ & $0.50(0.20)$ & $3.40(0.30)$ \\
\hline & $P$ value (t-test) & 0.336 & 0.244 & 0.955 & $0.001^{*}$ \\
\hline \multirow[t]{3}{*}{ Vitablocs Mark II Glazed } & Arabic Qahwa & $1.38(0.32)$ & $1.76(0.39)$ & $0.38(0.29)$ & $2.67(0.20)$ \\
\hline & Cold Coffee & $1.69(0.68)$ & $2.01(0.80)$ & $0.33(0.33)$ & $2.58(0.24)$ \\
\hline & $P$ value (t-test) & 0.271 & 0.430 & 0.768 & 0.418 \\
\hline \multirow[t]{3}{*}{ Vitablocs Mark II Polished } & Arabic Qahwa & $1.81(0.36)$ & $2.13(0.61)$ & $0.32(0.28)$ & $2.73(0.23)$ \\
\hline & Cold Coffee & $1.33(0.26)$ & $2.54(0.50)$ & $1.20(0.57)$ & $2.62(0.37)$ \\
\hline & $P$ value (t-test) & $0.010^{*}$ & 0.165 & $0.002^{*}$ & 0.471 \\
\hline \multirow[t]{3}{*}{ Vita Suprinity Glazed } & Arabic Qahwa & $2.63(0.65)$ & $3.30(0.56)$ & $0.66(0.42)$ & $1.94(0.80)$ \\
\hline & Cold Coffee & $2.07(0.68)$ & $2.37(0.60)$ & $0.30(0.22)$ & $1.42(0.09)$ \\
\hline & $P$ value (t-test) & 0.108 & $0.007^{*}$ & 0.053 & 0.111 \\
\hline \multirow[t]{3}{*}{ Vita Suprinity Polished } & Arabic Qahwa & $1.55(0.42)$ & $1.90(0.51)$ & $0.35(0.19)$ & $2.61(0.22)$ \\
\hline & Cold Coffee & $1.21(0.44)$ & $2.20(0.43)$ & $1.00(0.20)$ & $1.86(0.55)$ \\
\hline & $P$ value (t-test) & 0.129 & 0.217 & $0.000^{*}$ & $0.003^{*}$ \\
\hline
\end{tabular}

${ }^{*}=p \leq 0.05 ;$ Significant

Table 5 Two-way repeated measure ANOVA of ceramic materials, immersions, and surface roughness types (Account for within individual variations and between individual variations)

\begin{tabular}{|c|c|c|c|c|c|c|}
\hline \multirow[t]{2}{*}{ Parameter } & \multicolumn{3}{|c|}{ Changes in surface roughness (Ra) } & \multicolumn{3}{|c|}{ Mean color changes $\left(\Delta \mathrm{E}^{*}\right)$} \\
\hline & $\begin{array}{l}\text { Type III Wald Chi- } \\
\text { Square }\end{array}$ & Df & Sig & $\begin{array}{l}\text { Type III Wald Chi- } \\
\text { Square }\end{array}$ & Df & Sig \\
\hline Type of ceramic & 0.240 & 2 & 0.887 & 131.447 & 2 & $0.000^{*}$ \\
\hline Surface treatment & 4.967 & 1 & $0.026^{*}$ & 8.268 & 1 & $0.004^{*}$ \\
\hline Immersion type & 18.899 & 1 & $0.000^{*}$ & 1.944 & 1 & 0.163 \\
\hline Type of ceramic * Surface treatment & 14.004 & 2 & $0.001^{*}$ & 8.014 & 2 & $0.018^{*}$ \\
\hline Type of ceramic * Immersion type & 2.868 & 2 & 0.238 & 27.698 & 2 & $0.000^{*}$ \\
\hline Surface treatment ${ }^{*}$ Immersion type & 12.435 & 1 & $0.000^{*}$ & 0.010 & 1 & 0.919 \\
\hline $\begin{array}{l}\text { Type of ceramic * Surface treatment * Immer- } \\
\text { sion type }\end{array}$ & 31.471 & 2 & $0.000^{*}$ & 2.004 & 2 & 0.367 \\
\hline
\end{tabular}

* $=p \leq 0.05$; Significant

VS and between polished VE and VS subgroups in $\Delta \mathrm{E}^{*}$ of coffee type.

\section{Surface roughness and mean color change}

The Ra mean values for the tested CAD/CAM restorative materials were $0.59 \mu \mathrm{m}(\mathrm{VE}), 0.56 \mu \mathrm{m}(\mathrm{VM} \mathrm{II})$, and $0.58 \mu \mathrm{m}$ (VS), higher than the value recorded by Egilmez et al.[3] (0.012) for VE. However, Ra mean was lower than the values obtained by Al Moaleem et al. [14] (1.26) for VM II, Vasiliu et al. [28] (0.12) for feldspathic porcelain, and Qabel et al.[29] (0.17) for CAD/CAM materials. Although the recorded $\Delta \mathrm{E}^{*}$ values were 1.96 (VS), 2.65 (VM II), and 3.07(VE) within the clinically acceptable values for the three tested materials, these values are consistent with Subaşi et al. [30] (slightly above 2) for VS, Sarikaya et al.[18] (2.094) for VM II, and Colombo et al. [31] $(<3.3)$ for Zirconia. However, $\Delta E^{*}$ values were lower than (3.83 and 4.9) recorded by Saba et al. [17] for VE and VM II and Abu-Obaid et al.[32] ( $<3.3$ for VE, VM II, VS). However, the values were higher than that of Alp et al. 
A. Glazed hot Arabic Qahwa

VE

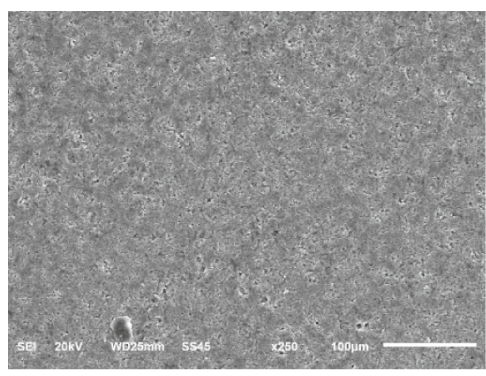

VM II

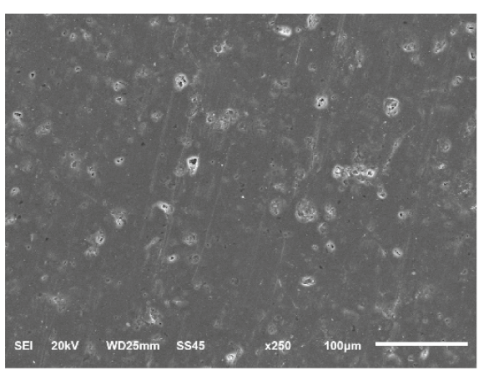

VS

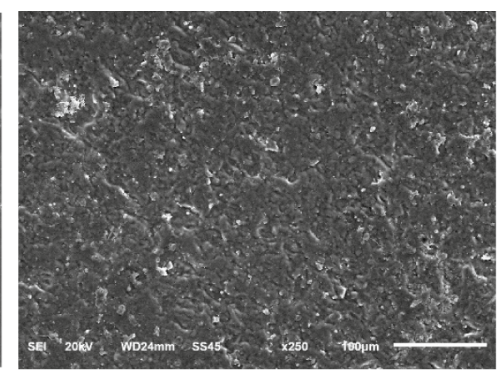

B. Polished Cold Coffee drink

VE

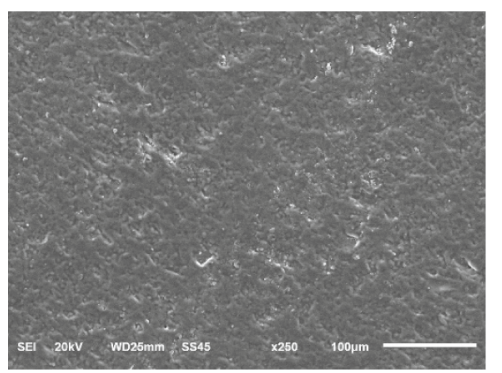

VM II

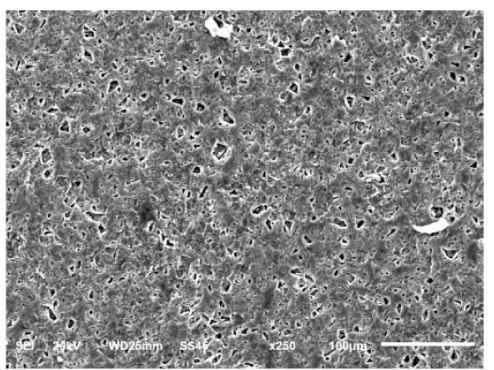

VS

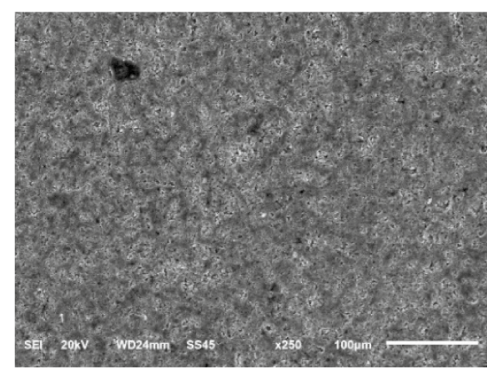

Fig. 4 SEM images of tested CAD/CAM restorative materials "VE, VM II, VS" at X 250 magnification after immersion in staining materials and thermocycling. A Glazed hot Arabic Qahwa, B Polished Cold Coffee sample

[12] and $\mathrm{Al}$ Moaleem et al. [14] who documented lower values than 1.0 for VS and 0.73 for VM II and Zirconia.

Surface roughness plays a crucial role in maintaining the surface values and preventing extrinsic discoloration [11]. Results showed that the surface roughness of the samples before and after thermocycling differed and that thermocycling had a significant impact on Ra, especially on the polished surfaces. The mean Ra values were 0.51 , $0.35,0.48$ and $0.68,0.76,0.67 \mu \mathrm{m}$ for glazed and polished samples of VE, VM II, and VS, respectively. Similar values were obtained by Alhabdan et al.[33] who recorded $0.56 \mu \mathrm{m}$ for glazed surfaces of feldspathic ceramic. However, these were higher than values recorded by Flury et al.[34] $0.20 \mu \mathrm{m}$ for VM II after polishing, much lower than glazed and polished values recorded by Kozmacs et al.[11] for monolithic zirconium dioxide crowns.

\section{Surface treatments and Ra measurements}

Milled zirconia that reinforced lithium disilicate glassceramic (VS) showed more significant changes when compared to the heat-pressed glossing and Ra. For VS before and after thermocycling, Vasiliu et al.[28] reported Ra values of 0.02 and $0.04 \mu \mathrm{m}$ for glazed samples. However, Ra values were $0.3 \mu \mathrm{m}$ for polished samples. Similarly, VS exhibited significantly lower roughness
$(0.69 \mu \mathrm{m})$ and higher gloss when compared with E.max CAD/CAM restorative material [35]. In another study, the Ra values recorded in VM II before and after thermocycling were 0.1 and $0.08 \mu \mathrm{m}$ for glazed samples, whereas they were 0.25 and $0.26 \mu \mathrm{m}$ for polished samples [28]. The present study records higher Ra values for glazed and polished samples for VS $(0.48$ and $0.67 \mu \mathrm{m})$ and VM II $(0.35$ and $0.76 \mu \mathrm{m})$, which may be attributed to the different polishing techniques, materials, and the Ra machine used. Egilmez et al.[13] stated that the tested materials exhibited different $\mathrm{Ra}$ values and surface topographies for VE $(0.011 \mu \mathrm{m})$, lower than values of 0.51 and $0.68 \mu \mathrm{m}$ for glazed or polished tested samples of the present study. The difference may be attributed to the technique used for sample preparation or the machine for Ra measurement. Al Moaleem et al.[14] showed mean Ra for glazed and polished Vitablocs Mark II (1.26 and $1.93 \mu \mathrm{m})$, higher than the mean values obtained in the current study $(0.35$ and $0.76 \mu \mathrm{m}$, respectively). The same study recorded $\mathrm{Ra}$ of 1.32 and $2.23 \mu \mathrm{m}$ for glazed and polished Zirconia samples showing significant differences between VM II and Zirconia. The results of the present study are the same for the glazed and polished samples of both VM II and VS, the sign between the two subgroups. 
Glazing or manual finishing and polishing are the most effective procedures that yield higher gloss and minimize the roughness of CAD/CAM silica-based VS. Overall, VS exhibited higher polishability than IPS E.max CAD [35], consistent with the results of the present study, providing slightly similar values for polished or glazed samples.

\section{Surface treatments and mean $\Delta \mathrm{E}^{*}$ measurements}

The external intraoral prostheses can be glazed or polished surfaces. The glaze layer is significant to the color stability of all-ceramic prostheses. The unglazed surfaces after occlusal intraorally adjustments should be avoided, and careful occlusal evaluation before cementation should be done [36]. The highest mean $\Delta E^{* *}$ was 3.03 for glazed VE and 3.12 for polished VE samples (without significant differences). Those values were slightly higher but somewhat lower than the values obtained (3.17-3.56) for $\mathrm{VE}$ polished samples [16], and this range was clinically acceptable. Abuobaid et al. [32] recorded $\Delta E^{*} 2.54 \pm 0.27$ for polished VE and $1.17 \pm 0.59$ for reglazed samples. Vasiliu et al.[28] documented 1.35 for the hybrid ceramic, after being exposed to hot and cold coffee. Acar et al. [21] concluded that VE glazed specimens were lower $\Delta \mathrm{E}^{*}$ than polished specimens for all-ceramic materials tested. In addition, when polished with different polishing materials, $\Delta E^{*}$ VE values were at an acceptable level for all the ceramic materials. All these values $[21,28,32]$ are slightly lower than the VE values of the present study despite that all $\Delta \mathrm{E}^{*}$ are clinical in acceptable range $\left(1<\left(\Delta \mathrm{E}^{*}-<3.7\right)\right.$ $[18,22]$.

For feldspathic CAD/CAM restorative materials (VM II), Sarikaya et al. [18] proposed that the feldspathic and low-fusing porcelain specimens were more color-stable as glazed versus polished ones regardless of whether stained with the coffee solution or other staining materials. VM II in form of glazed and polished samples with different polishing materials demonstrated that the $\Delta \mathrm{E}^{*}$ values were at an acceptable level $\left(1<\left(\Delta \mathrm{E}^{*}-<3.7\right)\right.$ without significant differences between all-ceramic tested materials [18]. In the present study, no significant differences were found between glazed (2.62) and polished (2.68) based on clinically acceptable color changes. AbuObaid et al. [32] recorded 2.39 for polished VM II samples after immersing in coffee. All the tested glazed or polished feldspathic metal-ceramic materials shown significant differences in the parameter of $\Delta \mathrm{E}^{*}$ for the tested groups after immersing in Khat extract [37].

Concerning $\Delta \mathrm{E}^{*}$ of VS, significant differences were present between the glazed (1.68) and polished (2.23) samples, although these values were slightly lower than values recorded $2.36 \pm 0.66$ for polished samples after staining and $0.99 \pm 0.54$ after re-glazing [32]. Polished surfaces after crown recontouring or occlusal adjustments should be avoided and reglazed before definitive cementation [22, 24]. Alp et al. [12] concluded that material type had a significant effect on the color difference after coffee immersion and thermocycling. However, the values were within the clinical acceptability threshold $(<1.8$ units). Similarly, a significant difference was detected between glazed and polished vs. subgroups samples with a p-value $<$ of 0.012 in the existing study. Additionally, significant color changes after immersion and thermocycling in acidic or Arabic coffee drinks were noticed. However, these changes were more considerable in polished porcelain specimens than those in glazed specimens for all CAD/CAM restorative materials [22, 24].

\section{Thermocycling and measurements}

Thermocycling is a widespread process of artificially enhanced ceramics aging since it replicates the oral environment as an extrinsic influence $[8,30,38]$. The water aging procedure contains identical thermal variations with baths extending from -5 to $55^{\circ} \mathrm{C}$ for several cycles. This process can affect the durability of the prosthesis, and it can simulate the performance of the ceramic restoration in the oral environment [8, 39]. Thermocycling with coffee immersion produced a significant mean $\Delta \mathrm{E}^{*}$ among monolithic teeth, base acrylic resin, and conventionally processed acrylic resin materials, used for dentures fabrications when compared with red wine [39]. The aging processes for glazed or polished samples of ceramic affected milled ceramic more than the heat press. In addition, the Zirconia reinforced lithium silicate glass-ceramic experienced a more significant change when carrying out color parameter values [28]. This was consistent with the results of the current study since VE recorded the highest $\Delta \mathrm{E}^{*}$ among glazed 3.15 and polished samples 3.40 of the cold coffee drink when compared with other tested materials after coffee staining and immersion. Acar et al. demonstrated that thermocycling in hot or cold coffee caused a clinically unacceptable color change for resin nano-ceramic and nano-composite resin materials as compared with hybrid ceramic VE, which was clinically acceptable and lower than 2.0 unit [21]. In this study, glazed samples of VE demonstrated less color change than polished specimens for all-porcelain materials tested after hot and cold coffee immersion and thermocycling.

Abu-Obaid et al. [32] estimated $\Delta E^{*}$ values for the glazed VE ceramic materials after hot coffee staining $(2.54 \pm 0.27)$. Vasiliu et al.[28] concluded that $\Delta E^{*}$ of VE or hybrid ceramic was 1.35 after being exposed to hot and cold coffee, and the outcome was clinically acceptable for the tested thickness. Sagsoz et al. [40] recorded $\Delta \mathrm{E}^{*}$ of 2.0 and less for glazed VE after 4 weeks of coffee staining. In contrast to the results obtained by El Sayed 
et al. [41] who recorded a high and unacceptable clinical average color change $(7.95 \pm 0.36)$ for the VE ceramic and $\Delta E^{*}$ of 4.90 for VE after coffee immersion. [17]

Sarikaya et al. [18] suggested that VM II specimens were more color-stable for glazed than polished, regardless of whether stained with the hot coffee solution or other cold staining materials. Palla et al. [36] stated that Vita Mark II in form of glazed and polished samples using different polishing materials were acceptable $\Delta \mathrm{E}^{*}$ for all tested ceramic materials. Another study recorded the $\Delta \mathrm{E}^{*}(2.39 \pm 0.54)$ for VM II upon staining in hot coffee after 4 weeks [32]. All previously mentioned values are similar to the results obtained in this study, which are between 2.67 and 2.58 for glazed samples and 2.73 and 2.62 for polished samples immersed in Arabic Qahwa and cold coffee, respectively. A higher value is registered for glazed samples of VM II (3.83) after coffee immersion [17]. To raise the discoloration resistance, glazing is recommended after surface alteration for all the CAD/CAM restorative materials [32].

After exploring the effect of coffee staining solution with 5000 thermocycling cycles for glazed Zirconia reinforced lithium, silicate VS samples were significant $\left(\Delta \mathrm{E}^{*}\right)$ when compared with other tested materials, which were within the clinically acceptable parameters [30]. This study showed significant differences $\left(\Delta E^{*}\right)$ among polished specimens and within acceptable limits after hot or cold coffee immersions and thermocycling. Vasiliu et al. [28] showed that VS color and feldspathic glass-ceramic were more affected by the aging and thermocycling, causing glazed samples to be rougher, having a significant impact on color translucency (lesser than 2 for VS samples). Alp et al. [12] concluded that VS and lithium disilicate treated with different surface finishing procedures (glazing or polishing) have significant differences and clinically acceptable for color changes after coffee thermocycling. This is consistent with the findings of this study, showing significant differences of P-value $<0.003$ between glazed and polished samples after hot or cold coffee immersion with the VS samples.

Significant differences for Ra were shown between the different tested parameter (ceramic, surface treatment, and immersion), consistent with previously published results $[13,28,35]$. The same findings were recorded in the $\Delta \mathrm{E}^{*}$ values after immersion and color change measurements, consistent with previous studies [12, 13, 32, 36,38 ] that demonstrated significant differences between two surface treatments and material types. This study was conducted with only one hot, cold coffee, and polishing with one selected kit. Future studies should focus on other staining solutions, polishing kits, and more samples.

\section{Conclusions}

This colorimetric in-vitro study showed that after surface treatments and staining with different coffee solutions:

- The mean Surface roughness increased for all sample groups and also the mean colour changes with the highest differences in VE and those in VS but within clinically acceptable limits.

- Increased surface roughness was observed in all the glazed with polished subgroups post-immersion and thermocycling. It was highest for polished VM II group. However, mean color changes higher values were noticed for VS group but within range of clinical acceptance.

- Within glazed immersion groups, no mean color changes were observed however, surface roughness changes were higher in VE cold coffee samples. Within polished immersion groups, higher Ra changes were found in VM II and VS cold coffee subgroups. Substantial mean color changes were also recorded in VE (cold coffee) and VS (Arabic Qahwa) polished subgroups but within clinical acceptance.

- SEM images showed more roughness for the polished samples than the glazed samples.

\section{Abbreviations}

Ra: Surface roughness; CAG/CAM: Computer-aided design/computer-aided manufacturing; $\triangle E$ : Mean color changes; VS: Vita Suprinity; VE: Vita Enamic;VM II: Vitablocs Mark II.

\section{Acknowledgements}

Not applicable.

\section{Authors' contributions}

"Conceptualization, M.M.Al. and A.P.; methodology, N.M.Al.; software, AK.A.S. and L.I.A.; formal analysis, M.M.Al.; investigation, A. M. S. and A.O.S; data curation, M.M.Al. and A.P.; writing — original draft preparation, and writing review and editing, M.S.; visualization. All authors read and approved the final manuscript.

\section{Funding}

No funding was obtained for this study.

\section{Availability of data and materials}

The datasets used and/or analyzed during the current study available from the corresponding author on reasonable request.

\section{Declarations}

Ethics approval and consent to participate

Ethical approval was taken from the standing committee for scientific research ethics Jazan University (HAPO-10-Z-001) reference number REC41/5 /126 on 13 May 2020.

Consent for publication Not applicable. 


\section{Competing interests}

The authors declare that they have no competing interests.

\section{Author details}

${ }^{1}$ Prosthetic Department, College of Dentistry, King Khalid University, Abha, Kingdom of Saudi Arabia. ${ }^{2}$ Applied Medical Sciences College, King Khalid University, Abha, Kingdom of Saudi Arabia. ${ }^{3}$ Department of Prosthetic Dental Science, College of Dentistry, Jazan University, Jazan 45142, Kingdom of Saudi Arabia. ${ }^{4}$ Intern Department, College of Dentistry, Jazan University, Jazan, Kingdom of Saudi Arabia.

Received: 19 December 2020 Accepted: 11 August 2021

Published online: 30 August 2021

\section{References}

1. Leinfelder KF. Porcelain esthetics for the 21st century. J Am Dent Assoc. 2000;131(Suppl):47S-51S.

2. Joiner A. Tooth colour: a review of the literature. J Dent. 2004;32(Suppl 1):3-12.

3. Dietschi D. Layering concepts in anterior composite restorations. J Adhes Dent. 2001;3(1):71-80.

4. Nasr E, Makhlouf AC, Zebouni E, Makzoume J. All-ceramic computeraided design and computer-aided manufacturing restorations: evolution of structures and criteria for clinical application. J Contemp Dent Pract. 2019;20(4):516-23.

5. Liu M-C, Aquilino SA, Gratton DG, Ou K-L, Lin C-C, Medicine C. Relative translucency and surface roughness of four yttrium-stabilized tetragonal zirconia polycrystalline-based dental restorations. J Exp Clin Med. 2013;5(1):22-4.

6. Giordano R. Materials for chairside CAD/CAM-produced restorations. J Am Dent Assoc. 2006;137(Suppl):14S-21S.

7. Denry I, Kelly JR. State of the art of zirconia for dental applications. Dent Mater. 2008:24(3):299-307.

8. Flinn BD, deGroot DA, Mancl LA, Raigrodski AJ. Accelerated aging characteristics of three yttria-stabilized tetragonal zirconia polycrystalline dental materials. J Prosthet Dent. 2012;108(4):223-30.

9. Saridag S, Tak O, Alniacik G. Basic properties and types of zirconia: an overview. World J Stomatol. 2013:2(3):40-7.

10. Wang L, Liu Y, Si W, Feng H, Tao Y, Ma Z. Friction and wear behaviors of dental ceramics against natural tooth enamel. J Eur Ceram Soc. 2012;32(11):2599-606.

11. Kozmacs C, Hollmann B, Arnold WH, Naumova E, Piwowarczyk A. Polishing of monolithic zirconia crowns-results of different dental practitioner groups. Dent J (Basel). 2017;5(4):30.

12. Alp G, Subasi MG, Johnston WM, Yilmaz B. Effect of surface treatments and coffee thermocycling on the color and translucency of CAD-CAM monolithic glass-ceramic. J Prosthet Dent. 2018;120(2):263-8.

13. Egilmez F, Ergun G, Cekic-Nagas I, Vallittu PK, Lassila LVJ. Comparative color and surface parameters of current esthetic restorative CAD/CAM materials. J Adv Prosthodont. 2018;10(1):32-42.

14. Moaleem MMA, AlSanosy R, Ahmari NMA, Shariff M, Alshadidi AA, Alhazmi HA, et al. Effects of Khat on surface roughness and color of feldspathic and zirconia porcelain materials under simulated oral cavity conditions. Medicina (Kaunas). 2020;56(5):234.

15. Lee JH, Kim SH, Han JS, Yeo IL, Yoon HI. Optical and surface properties of monolithic zirconia after simulated toothbrushing. Materials (Basel). 2019;12(7):1158

16. Sarikaya I, Yerliyurt K, Hayran Y. Effect of surface finishing on the colour stability and translucency of dental ceramics. BMC Oral Health. 2018;18(1):40

17. Saba DA, Salama RA, Haridy R. Effect of different beverages on the color stability and microhardness of CAD/CAM hybrid versus feldspathic ceramic blocks: an in-vitro study. Future Dent Jo. 2017;3(2):61-6.

18. Sarikaya I, Güler AU. Effects of different surface treatments on the color stability of various dental porcelains. J Dent Sci. 2011;6(2):65-71.

19. Kursoglu P, Karagoz Motro PF, Kazazoglu E. Correlation of surface texture with the stainability of ceramics. J Prosthet Dent. 2014;112(2):306-13.

20. Gupta R, Parkash H, Shah N, Jain V. A spectrophotometric evaluation of color changes of various tooth colored veneering materials after exposure to commonly consumed beverages. J Indian Prosthodont Soc. 2005;5(2):72.

21. Acar O, Yilmaz B, Altintas SH, Chandrasekaran I, Johnston WM. Color stainability of CAD/CAM and nanocomposite resin materials. J Prosthet Dent. 2016;115(1):71-5

22. Alghazali N, Hakami AA, AlAjlan GA, Alotaibi RM, Alabdulwahab FN, AlQuraishi LA, et al. Influence of the arabic-coffee on the overall color of glazed or polished porcelain veneers-study. Open Dent J. 2019;13(1):364-70.

23. Alghazali N, Burnside G, Moallem M, Smith P, Preston A, Jarad FD. Assessment of perceptibility and acceptability of color difference of denture teeth. J Dent. 2012;40(Suppl 1):e10-7.

24. Abdalkadeer HK, Almarshedy SM, Al Ahmari NM, Al Moaleem AM, Aldosari AA, AI Ghazali NA. Influence of the Coca-Cola drinks on the overall color of glazed or polished porcelain veneers fabricated from different materials and thicknesses: an in vitro study. J Contemp Dent Pract. 2020;21(1):56-61.

25. Haralur SB, Rage SAN, Alhassan MF. Effect of hydrothermal aging and beverages on color stability of lithium disilicate and zirconia based ceramics. Medicina (Kaunas). 2019;55(11):749

26. Yannikakis SA, Zissis AJ, Polyzois GL, Caroni C. Color stability of provisional resin restorative materials. J Prosthet Dent. 1998:80(5):533-9.

27. Al-Moaleem MM, Shah FK, Khan NS, Porwal A. The effect of thermocycling on the bonding of different restorative materials to access opening through porcelain fused to metal restorations. J Adv Prosthodont. 2011;3(4):186-9.

28. Vasiliu RD, Porojan SD, Birdeanu MI, Porojan L. Effect of thermocycling, surface treatments and microstructure on the optical properties and roughness of CAD-CAM and heat-pressed glass ceramics. Materials (Basel). 2020;13(2):381.

29. Qabel F, Talaei R, Saeedi S, Ghorbani R, Ameli N. Comparative effect of three polishing systems on porcelain surface roughness after orthodontic bracket debonding and composite resin removal: an atomic force microscopy. APOS Trends Orthod. 2019;9(4):223-9.

30. Subasi MG, Alp G, Johnston WM, Yilmaz B. Effects of fabrication and shading technique on the color and translucency of new-generation translucent zirconia after coffee thermocycling. J Prosthet Dent. 2018;120(4):603-8

31. Colombo M, Cavallo M, Miegge M, Dagna A, Beltrami R, Chiesa M, et al. Color stability of CAD/CAM Zirconia ceramics following exposure to acidic and staining drinks. J Clin Exp Dent. 2017;9(11):e1297-303.

32. Abu-Obaid A, AlMawash A, Alyabis N, Alzaaqi N. An in vitro evaluation of the effect of polishing on the stainability of different CAD/CAM ceramic materials. Saudi Dent J. 2020;32(3):135-41.

33. Alhabdan AA, El-Hejazi AA. Comparison of surface roughness of ceramics after polishing with different intraoral polishing systems using profilometer and SEM. J Dent Health Oral Disord Ther. 2015;2(3):1-11.

34. Flury S, Lussi A, Zimmerli B. Performance of different polishing techniques for direct CAD/CAM ceramic restorations. Oper Dent. 2010;35(4):470-81.

35. Vichi A, Fabian Fonzar R, Goracci C, Carrabba M, Ferrari M. Effect of finishing and polishing on roughness and gloss of lithium disilicate and lithium silicate zirconia reinforced glass ceramic for CAD/CAM systems. Oper Dent. 2018:43(1):90-100.

36. Palla ES, Kontonasaki E, Kantiranis N, Papadopoulou L, Zorba T, Paraskevopoulos KM, et al. Color stability of lithium disilicate ceramics after aging and immersion in common beverages. J Prosthet Dent. 2018:119(4):632-42.

37. Al-Moaleem MMHHE, Dafalla OM, Alamir OH, Dahas ZA, Alqasemi WI, Al-Sanabani FA. Evaluation of color changes and surface topography of different feldspathic ceramic materials after Khat, Catha edulis extract immersion. Biosc Biotechnol Res Comm. 2020;13(1):160-8.

38. Arocha MA, Mayoral JR, Lefever D, Mercade M, Basilio J, Roig M. Color stability of siloranes versus methacrylate-based composites after immersion in staining solutions. Clin Oral Investig. 2013;17(6):1481-7.

39. Al-Qarni FD, Goodacre CJ, Kattadiyil MT, Baba NZ, Paravina RD. Stainability of acrylic resin materials used in CAD-CAM and conventional complete dentures. J Prosthet Dent. 2020;123(6):880-7.

40. Sagsoz O, Demirci T, Demirci G, Sagsoz NP, Yildiz M. The effects of different polishing techniques on the staining resistance of CAD/CAM resinceramics. J Adv Prosthodont. 2016;8(6):417-22. 
41. El Sayed SM, Basheer RR, Bahgat SFA. Color stability and fracture resistance of laminate veneers using different restorative materials and techniques. Egypt Dent J. 2016;62:1-15.

\section{Publisher's Note}

Springer Nature remains neutral with regard to jurisdictional claims in published maps and institutional affiliations.
Ready to submit your research? Choose BMC and benefit from:

- fast, convenient online submission

- thorough peer review by experienced researchers in your field

- rapid publication on acceptance

- support for research data, including large and complex data types

- gold Open Access which fosters wider collaboration and increased citations

- maximum visibility for your research: over 100M website views per year

At BMC, research is always in progress.

Learn more biomedcentral.com/submissions 